This is an electronic reprint of the original article. This reprint may differ from the original in pagination and typographic detail.

Author(s): Valleala, Ulla Maija; Herranen, Sanna; Collin, Kaija; Paloniemi, Susanna

Title: $\quad$ Fostering learning opportunities through employee participation amid organizational change

Year: $\quad 2015$

Version:

Please cite the original version:

Valleala, U. M., Herranen, S., Collin, K., \& Paloniemi, S. (2015). Fostering learning opportunities through employee participation amid organizational change. Vocations and Learning, 8(1), 1-34. https://doi.org/10.1007/s12186-014-9121-0

All material supplied via JYX is protected by copyright and other intellectual property rights, and duplication or sale of all or part of any of the repository collections is not permitted, except that material may be duplicated by you for your research use or educational purposes in electronic or print form. You must obtain permission for any other use. Electronic or print copies may not be offered, whether for sale or otherwise to anyone who is not an authorised user. 


\title{
Fostering learning opportunities through employee participation amid organizational change
}

\begin{abstract}
Health care organizations are facing rapid changes, frequently involving modification of existing procedures. The case study reported here examined change processes and learning in a health care organization. The organizational change in question occurred in the emergency clinic of a Finnish central hospital where a new action model for shift-specific nursing supervision was being introduced. The aim of this study was to investigate some of the employee participation and learning opportunities amid this organizational change. The data collection was ethnographically informed, and the data consisted of audio-recorded and observed meetings, observations of the new action model, and field interviews which were analyzed qualitatively. The change appeared to occur in four phases: preparation, planning, discussion, and implementation. Structures (e.g. regular meetings open to the entire staff) and practices (e.g. open discussion) facilitating participation in the phases of the change were prerequisites for participation by individual employees, but participation was not made structurally possible throughout the change. The study confirmed the importance of participation for learning within change. In the change, participation in the form of identity work denoted individual-level learning opportunities, and participation in the form of suggestions for new practices and expression of problems facilitated organization-level learning opportunities. In this study, participation manifested itself as a more multifaceted phenomenon than in previous studies. This study provided new knowledge on employee participation and its manifestations in micro-level interaction, as well as on both individuallevel and organization-level learning opportunities in organizational change.
\end{abstract}

Keywords: Organizational change, participation, learning opportunities, learning at work, health care

\section{Introduction}

Health care organizations are facing rapid changes, frequently involving modification of existing procedures. In this situation, care units are required to learn new practices that will maintain high-quality care (Tucker et al. 2007). The case study reported here examined change processes and learning in a health care organization. It forms part of a larger research and development project conducted in a regional emergency outpatient clinic in a Finnish central hospital. In this paper, we focus on a process of change that was carried out in the emergency clinic due to a projected increase in patient volume. Before the change, there were approximately 70,000 patient visits to the clinic per year. Following the reorganization of regional emergency care, the number of patient visits for primary health care was expected to increase by 17,000 . This impending increase led to a modification of the clinic's procedural model. In our study, we examined the change process as it affected nursing in the clinic, and especially the new arrangements for the shift-specific supervision of nursing.

An important question in contemporary working life is how work should be organized both to develop the organization and to enhance employees' learning. Organizational changes can threaten employees' opportunities for learning, but can also improve them (Argyris and Schön 
1996). It is thus important to understand the features of change that can promote rather than hinder learning in organizations. In this study, we approach learning from a sociocultural viewpoint, according to which learning at work has been characterized as situated, informal, and incidental (Watkins and Marsick 1992; Lave 1993). From this perspective, learning can be seen as a natural aspect of everyday work, and work itself as a rich source of learning. Learning is incorporated within everyday problem-solving (Argyris and Schön 1996) and the purpose and direction of learning largely derive from the goals of the work itself, arising naturally out of the demands and challenges of the job and the social interaction in the workplace. Research on learning at work has also emphasized the importance of learning through co-operation and interaction with colleagues and other networks (see e.g. Wenger 1998; Järvinen and Poikela 2001; Billett 2004; Collin 2002; Collin and Paloniemi 2008; Poell and Van der Krogt 2010).

We see learning as occurring in interaction and in social workplace activities (see Brown and Duguid 1991; Easterby-Smith et al. 2000). It has been noted that it is hard to attain concrete knowledge on workplace learning outcomes by empirical research (Lines 2005). Instead, in this paper, we see it as fruitful to set out some of the learning opportunities that can arise in organizational change. By learning opportunities we mean those features of interaction that can produce beneficial learning outcomes, for example, new knowledge, roles, or practices (see Gherardi and Nicolini 2001). Identifying these may help key actors to maintain or increase learning during processes of organizational change. Knowledge of this kind may also help in preventing the threats to employees' learning and wellbeing that can arise in times of change.

The structure of this article follows the steps of the qualitative research process followed for the study. This structure was utilized due to the process-like nature of the data-driven qualitative analysis, which cannot easily be reported within the traditional academic structure. Thus, we shall first present previous studies on organizational change and learning within organizational change, particularly within health care. Thereafter, we shall define the scientific gap this study aims to contribute to, and broadly outline a research objective, before describing the context, methods and data of this study. The findings of each step of the analysis are reported immediately after description of the analysis of a given step (hence "Analysis, step one" is followed by "Findings, step one"). The specific research questions are set out after the first step of the analysis, in conjunction with previous studies of a prime theoretical concept which we identified in our data in this step of the analysis. The two steps of the analysis and findings are followed by our conclusions, and finally, by an examination of the limitations of the study and suggestions for further research.

\section{Organizational change in health care}

Organizational change can be defined as a significant modification of the prevailing arrangements of an organization, and the diffusion of a new practice or procedure in an organization (Suddaby and Greenwood 2009). Organizational changes are carried out for a number of reasons, including adaptation to changes in the context, introduction of new functions or technology, and reductions in funding (Burke 2008; Edmondson et al. 2001; Choi et al. 2011). Organizations do not change by themselves; rather, it is the members of organizations who plan and implement changes. In hierarchical organizations such as hospitals, the role of managers in initiating and organizing changes is significant (Tucker and Edmondson 2003; Burke 2008; Choi et al. 2011). In recent approaches to organizational 
change, the phenomenon is further regarded as a continuous and ongoing process; thus, particular organizational structures and practices are always temporary by nature (Tsoukas and Chia 2002). This means that changes are not straight top-down processes; in fact, interaction and negotiations between managers and staff play an essential role in change processes (Choi et al. 2011; Thomas and Hardy 2011). In the present study we saw organizational change as occurring within interactions, and as being a manager-led process. In other words, the situation was one of intentional modifications, arrangements, and the implementation of new practices in an organization, initiated and organized by management, and implemented by the entire organization staff.

The processes of organizational change in health care have been investigated in a few studies (Bate 2000; Bunniss and Kelly 2008; Dobers and Söderholm 2009; Edmondson et al. 2001), yielding information on the phases of change. Edmondson and colleagues (2001) studied the process of establishing new surgery technology in surgical teams. They found that, in successful teams, the implementation process occurred in four phases: enrollment, preparation, trials, and reflection. The first phase, enrollment, was important for motivating the actors for change, e.g. defining roles and responsibilities; preparation included practicing of the new technology and generating psychological safety among team members; trials involved initial use of the technology; and reflection promoted shared meaning about the new technology. Dobers and Söderholm (2009) analyzed development projects in health care, specifically emphasizing the beginnings and endings of projects and transitions of consecutive projects. They divided the process into two phases: translation and inscription. At the start of a process, ideas and observed needs for development are translated into plans of action. Inscription refers to the end of a project, when materialized ideas are inscribed into reports and actions. Here, it should also be noted that the stages of change have been found to be non-linear, with the transitions from one stage to another emerging as ambiguous and uncertain (Kitson 2009; Edmondson et al. 2001).

\section{Learning within organizational change}

Previous research has approached the sociocultural conception of learning from different angles, namely communities of practice (Wenger 1998), a practice-based viewpoint (e.g. Hager et al. 2012), and identity (e.g. Billett and Somerville 2004). More specifically, particularly in terms of learning within organizational change, the concepts of leadership, training, participation, identity work, and communication and feedback emerge as central aspects.

Studies on leadership and team learning (e.g. Edmondson et al. 2001; Bernstrøm and Kjekshus 2012; Ortega et al. 2013) have argued that leader behaviours play an essential role in changes; in this view, change is not executed solely by top management but by leaders at all levels of the organization. Furthermore, change-oriented leadership appears to play a crucial role in team learning (Ortega et al. 2013). Teams have a particular role to play, since they can be seen as sites where team members give voice to conflicting and problematic aspects of work practice (Engeström and Middleton 1996), and where a safe and favourable environment for learning can be promoted (Bunderson and Boumgarden 2010).

Participation studies (e.g. Easterby-Smith et al. 2000; Lines 2005; Sverke et al. 2008) have indicated that employee participation is one of the major explanations of successful organizational change. Employee participation has been viewed as enhancing learning, since 
it gathers together employees who have different kinds of experience, skills, and knowledge (Kitzmiller et al. 2010).

In terms of professional agency and identity work, one critical question has been how organizations can manage employees' work and create sustainable changes without jeopardizing employees' positive identities, organizational commitment, and satisfaction in their work (Vähäsantanen 2013). In situations of change, learning as identity work is also bound up with meeting the new responsibilities that people must undertake, for example, via the creation of new roles and knowledge, and the production or reproduction of new practices (see Gherardi and Nicolini 2001). In health care, new work roles and practices have been created, for example, in situations where tasks previously performed by physicians have been transferred to nurses (Stenner and Courtenay 2008).

Training and development have been found to constitute a tool for individual members to embrace new practices in an organization (Conceição and Altman 2011). Moreover, formal culture-change training can improve the conceptions of staff concerning an impending or ongoing culture change (Munroe et al. 2011).

With reference to communication and feedback, research on new nursing roles has indicated that clear, open, and consistent communication between management and staff can decrease nurses' uncertainty about their new roles and help them to meet their new responsibilities (Miller et al. 2000; Miller and Apker 2002). It has also been suggested (Portoghese et al. 2012) that nurses will gain a greater emotional commitment to change if their expectations regarding the new measures move in a positive direction; furthermore, the social and information systems in the organization can help to shape these expectations. In connection with the central elements of job satisfaction and organizational commitment, the importance of frequent communication between management and employees has been underlined - the aim being that employees will understand the advantages of the changes for the organization and for themselves (Chih et al. 2012). In regard to feedback (e.g. Edmondson et al. 2001; Baker et al. 2013) studies suggest that, in order to achieve a feedback-friendly culture, one should consider the importance of leaders who will work towards a learning organization, generally establishing a psychologically safe workplace in which dialogue will become the norm and in which communication will be flexible across the organization.

Nevertheless, much remains to be discovered about how change processes occur and proceed in interactional situations in an organization, or about the kinds of challenges and opportunities for learning that they include. The present study investigated organizational change and learning on an interactional level, and thus it focused on the micro-level of action. This aspect has received relatively little attention in studies of organizational change (see Bjerregaard 2011; Choi et al. 2011), although it has been mentioned as important for change (Choi et al. 2011; Thomas and Hardy 2011) and also for learning (Tsoukas 2009). In our study, the aim was also to explore a combination of the two theoretical viewpoints (organizational change in health care and learning in organizational change) presented above. More specifically, we posed this question: What kinds of learning opportunities are manifested in the different phases of the change? There is no previous research on this topic; nevertheless, knowledge concerning the micro-level actions at different phases of a change will shed light on possibilities to enhance learning opportunities within the process as a whole. 


\section{The context, methods, and data of the study}

The main organizational arrangements examined in this study concerned the duties of the chief duty nurses and the division of labour in an emergency clinic. Within the clinic, experienced and skilled nurses work in rotation as chief duty nurses during their shift, one nurse at a time. The chief duty nurse functions as a shift-specific work leader in the emergency clinic. The new arrangements meant that particular duties that had previously been the responsibility of charge nurses ${ }^{1}$ were transferred to the chief duty nurses. It should be noted that the chief duty nursing model had been in use in the clinic for several years, but that, as part of the change, the duties and role of the chief duty nurse were modified. At the same time, the duties of the triage nurse ${ }^{2}$ were separated from those of the chief duty nurse.

In addition to this development of the duties of the chief duty nurse, a new action model, based on fast-track practice, was put into effect. The fast-track is a section of the clinic where minor medical cases, e.g. smaller wounds, are treated by a doctor-nurse work pair. Because of expansion in the work done and the growth in staff numbers, the shift roster system also had to be changed. To prepare for the increase in patient volume, the triage practices of the clinic were evaluated and developed in a new direction. Another important element in the change was modification of the treatment rooms to allow an expansion in the work done. The overall organizational change also included changes in the information systems. This latter change was not actually necessary in relation to the increased patient volume, but it was implemented along with the other changes. As will be explained in detail below, the changes were prepared and discussed in several meetings in the clinic; however, due to the continuous three-shift system, it was not possible for the entire staff to attend a meeting at any given time.

Because this study formed part of a larger research and development project, permission for the research had already been requested for the entire project from the hospital, university, and from the staff taking part in the study; thus, the permission was also valid for the present study. Patients attending the clinic were not subjects of the study; hence, there were no ethical issues concerning patients.

In this case study, ethnography was used as a method but not as a wider methodological approach (see Brewer 2000). This means that the data collection and data analysis were ethnographically informed. It should be noted that the aim of the study was not to investigate cultural aspects or the actors' interpretations of their culture (as happens in methodologically ethnographic studies). In this study, the ethnographical method implies that people's actions, and their social situations were examined in situ, within their natural context. Ethnography was assumed to provide an appropriate means to investigate processes and organizational change, with particular reference to the processual aspects of change, which in work organizations may be complex and multidirectional (Fine et al. 2009).

The reason for adopting ethnographically informed methods was also the constitutive aspect of learning at work, as identified in previous studies, meaning that learning occurs as an incidental activity intertwined with one's work. From this perspective, it is unprofitable to investigate learning opportunities as special educational occasions distinct from other activities, and it is more useful to view them as intrinsic to the work and to organizational

\footnotetext{
${ }^{1}$ The charge nurse is a middle nurse manager, working under the head nurse, and responsible for management responsibilities such as shift rosters.

${ }^{2}$ Triage means assessment of the urgency of treatment. Triage nurses meet patients individually, assess their treatment needs, and decide whether they are to be admitted to the clinic.
} 
practices (see Gherardi and Nicolini 2001; Nicolini and Meznar 1995). This led us to avoid focusing purely on situations where learning (as deliberate instruction) might be expected to occur, and instead to take a more holistic stance.

Our interest in real-life organizational processes was also the reason why only one clinic was selected for this study. Such a setting was well-suited to a case study approach, since within it we could observe how learning takes place in real-life organizational events (see Yin 1994), bearing in mind - as pointed out by Radley and Chamberlain (2012) - that 'the case study approach is sensitive to the context in which information is gathered'.

Table 1. The data collection of this study in chronological order

\begin{tabular}{|c|c|c|c|}
\hline $\begin{array}{l}\text { Occasions } \\
\text { observed or } \\
\text { interviews } \\
\text { conducted }\end{array}$ & Timing & Observers/Interviewers & $\begin{array}{l}\text { Duration of occasions } \\
\text { and number of pages } \\
\text { of transcriptions or } \\
\text { field notes }\end{array}$ \\
\hline $\begin{array}{l}\text { Everyday } \\
\text { action in the } \\
\text { emergency } \\
\text { clinic (not } \\
\text { included in the } \\
\text { data analyzed) }\end{array}$ & $\begin{array}{l}12 \text { March } \\
2010-29 \\
\text { October } \\
2010\end{array}$ & $\begin{array}{l}\text { First, third, and fourth } \\
\text { writer of the paper (two } \\
\text { observers at a time) }\end{array}$ & $\begin{array}{l}\text { Total } 85 \mathrm{~h} \text { of } \\
\text { observations; } 82 \text { pages } \\
\text { of field notes based on } \\
\text { observations }\end{array}$ \\
\hline $\begin{array}{l}16 \text { meetings in } \\
\text { which the } \\
\text { changes were } \\
\text { prepared, } \\
\text { planned, } \\
\text { discussed, and } \\
\text { evaluated (see } \\
\text { Table 2) }\end{array}$ & $\begin{array}{l}29 \text { April } \\
2010-17 \\
\text { May } 2011\end{array}$ & $\begin{array}{l}\text { All four writers (who } \\
\text { were present at the } \\
\text { meetings, two at a } \\
\text { time) }\end{array}$ & $\begin{array}{l}\text { Duration of meetings } \\
\text { varied between } 35 \mathrm{~min} \\
\text { and } 2 \mathrm{~h} 30 \text { min, with a } \\
\text { total } 21 \mathrm{~h} ; 487 \text { pages of } \\
\text { transcribed recordings } \\
\text { of meetings (except for } \\
\text { a statutory co- } \\
\text { determination meeting: } \\
5 \text { pages of field notes } \\
\text { based on observations) }\end{array}$ \\
\hline $\begin{array}{l}\text { Work of chief } \\
\text { duty nurses }\end{array}$ & $\begin{array}{l}\text { 18 January } \\
2011-11 \\
\text { April } 2011\end{array}$ & $\begin{array}{l}\text { First, second, and third } \\
\text { writer (two observers } \\
\text { at a time) }\end{array}$ & $\begin{array}{l}\text { A total of } 22 \mathrm{~h} \text { of } \\
\text { observations, } 34 \text { pages } \\
\text { of field notes based on } \\
\text { the observations. } \\
\text { Additionally, field } \\
\text { interviews of } 10 \text { chief } \\
\text { duty nurses and } 6 \\
\text { nursing teams (duration } \\
\text { varied between } 1 \text { min } \\
\text { and } 21 \text { min). In total, } \\
46 \text { pages of transcribed } \\
\text { interviews }\end{array}$ \\
\hline
\end{tabular}

The procedure for the data collection is presented in Table 1. It is set out chronologically, based on the beginning of each data collection phase. Altogether, we followed the change process reported in this paper for over one year. The total research project lasted $2 \frac{1}{2} 2$ years, within the period 2010-2012. The research project began with our observations of everyday 
actions taken in the emergency clinic. These observations were made in order to acquaint ourselves with the context surrounding the change process. Even though these data were not analyzed for this particular study, they gave us a good understanding of the context and of the everyday work practices of the clinic. The observations were performed during different times of the day and on different days of the week, in order to gather diverse data on everyday actions in the clinic. The impending organizational change emerged as a topic of interest while we were becoming acquainted with the context, on the basis of conversations with the management of the clinic.

The data consisted of observed and audio-recorded meetings held by the staff and managers of the clinic in which the changes were prepared, planned, discussed, and evaluated; observations of situations where the changes were implemented; and interviews with staff members about these implementations. Prior to attending the meetings examined in this study, we first planned and negotiated with the care managers regarding which meetings we could usefully attend and record. In so doing, we aimed to ensure that the data would, as far as possible, encompass the various processes and dimensions of the change. In addition, concerning the question of which events in the clinic's everyday procedures were connected with the change and which were not, we relied on the views of the care managers and on the discussions we conducted with the managers and with the staff. Furthermore, the participants in this study were determined by the persons who engaged in the various events occurring within the change. The analysis of the meetings was based on the transcribed recordings, except for the statutory co-determination meeting, which was not recorded because of the problematic facilities in which the meeting was held. The analysis of this meeting was based on the field notes.

In addition, we observed the work of the chief duty nurses to investigate how the implementation of the changes proceeded. On most occasions, there were two observers at a time, the purpose being to gather wider and more accurate observations than would have been possible by only one observer (here following the principles of collective ethnography) (Paloniemi and Collin 2010; Gordon et al. 2006; Woods et al. 2000). In addition, by basing the analysis and interpretations on the field notes of more than one observer, we aimed to increase the reliability of the study. Furthermore, during the observations, field interviews of ten chief duty nurses (out of the altogether twenty chief duty nurses of the clinic) and six care groups were carried out to investigate how the staff experienced the changes. The interviewed care groups were natural care groups of 2-4 nurses, working together in a given shift.

All the data, including the transcriptions and the field notes, were arranged chronologically, and the different types of data were analyzed in the same way. Observations and field interviews were used to validate each other. For example, we asked the care groups how they viewed the functionality of the new model, and also observed how the chief duty nurses worked in practice.

\section{The research objective: The broad focus}

To examine the kinds of learning opportunities manifested in the different phases of the change, it was first necessary to determine the nature of the change and how it proceeded. Thus, we first determined the phases and timing of the change process. After this, we examined the role of the aspects of learning in organizational change found in previous research in relation to those learning opportunities that emerged in this case. 


\section{Analysis, step one}

The data were read several times, with a view to identifying the main contents of the discussions and the actions taken. The data were also coded and categorized inductively according to the topics discussed or planned. An example of this coding is presented in Appendix 1. On the basis of this categorization, brief summaries (see Table 2) of the discussions of the meetings and actions were written to give the reader access to our data. This part of the analysis was informed by the principles of case study analysis (see Patton 2002). Next, we used as an analytical framework those aspects of learning in organizational change that had emerged in previous research. This denoted that leadership, training and support, identity work, and communication and feedback were used as theory-driven codes. This coding was done to the above-mentioned brief summaries and validated from the original data (see Table 2 and Appendix 1). However, concerning one of the categories, participation, it became obvious based on our data that its nature was different from the other categories. This category was not found as a content (e.g. training) of discussions or a way of action (e.g. communication), but rather as a structural prerequisite for the other categories and was thus a connective category of the other categories. This part of the analysis could be called theory-driven thematic analysis (see Braun and Clarke 2006), as we aimed to find out how the aspects in question emerged in our own data.

\section{Findings, step one}

\section{Organizational change: The phases, participants, and main contents of the phases}

On the basis of the main contents of the meetings and the observed chronology, the change appeared to occur in four phases: preparation, planning, discussion, and implementation (see Table 2). As observed in previous studies (e.g. Kitson 2009), the boundaries between the different phases were somewhat ambiguous. The discussions in the preparation phase concerned existing problems in the clinic. In the second development meeting, the head nurse wished to lead the small-group discussions in such a way as to prepare for the coming changes, but the groups mainly discussed existing problems. Thus, the second development meeting did not achieve the head nurse's aim of starting to plan the new practices and action models of the clinic (see also Extract 1). This meant that it was not possible to define the planning phase purely on the basis of the meetings or what was actually discussed in the planning group.

A statutory co-determination meeting was held, as well as a meeting of the work group for the division of labour. Although the main contents of these two meetings bore a closer resemblance to the meetings of the discussion phase, we included these meetings in the planning phase on the basis of the chronology. We determined the boundary between the discussion and the implementation phases on the basis of the date when new patient groups started to use the primary care services of the clinic.

Table 2. Phases, settings, timing, participants, and main contents in the organizational change process

\begin{tabular}{|l|l|l|l|l|l|}
\hline Phase & Settings & Participants & Brief summary of the main content & Aspects of & Connective \\
\hline
\end{tabular}




\begin{tabular}{|c|c|c|c|c|c|}
\hline & and timing & & & $\begin{array}{l}\text { learning within } \\
\text { organizational } \\
\text { change }\end{array}$ & aspect \\
\hline \multirow[t]{2}{*}{$\begin{array}{l}\text { Prepa } \\
\text { ration } \\
\text { phase }\end{array}$} & $\begin{array}{l}\text { First } \\
\text { developm } \\
\text { ent } \\
\text { meeting in } \\
\text { the clinic } \\
29 \text { April } \\
2010\end{array}$ & $\begin{array}{l}\text { Nursing } \\
\text { staff (about } \\
20 \\
\text { employees) } \\
\text { and } \\
\text { managemen } \\
\text { t of the } \\
\text { emergency } \\
\text { clinic (head } \\
\text { nurse, } \\
\text { charge } \\
\text { nurse, chief } \\
\text { physician, } \\
\text { senior ward } \\
\text { physician) }\end{array}$ & $\begin{array}{l}\text { Discussion of problems in the clinic (inadequate } \\
\text { cleanliness in the treatment rooms, problems with } \\
\text { the patient data system, training needs, shift } \\
\text { rosters, shortage of nurses in the trauma room, } \\
\text { backlogs) (Extract 7). }\end{array}$ & $\begin{array}{l}\text { Communication } \\
\text { as discussion } \\
\text { Training }\end{array}$ & \multirow{4}{*}{$\begin{array}{l}\text { Participatio } \\
\mathrm{n}\end{array}$} \\
\hline & $\begin{array}{l}\text { Second } \\
\text { developm } \\
\text { ent } \\
\text { meeting in } \\
\text { the clinic } \\
19 \text { August } \\
2010\end{array}$ & $\begin{array}{l}\text { Nursing } \\
\text { staff (about } \\
40 \\
\text { employees) } \\
\text { and } \\
\text { managemen } \\
\text { t of the } \\
\text { emergency } \\
\text { clinic (head } \\
\text { nurse, } \\
\text { charge } \\
\text { nurse, } \\
\text { senior ward } \\
\text { physician) }\end{array}$ & $\begin{array}{l}\text { The senior ward physician informed the staff } \\
\text { about the actions needed because of the increased } \\
\text { patient volume. General discussion on proposed } \\
\text { spatial changes in the clinic (treatment rooms, } \\
\text { etc.). Small-group discussions on training } \\
\text { needs, shift rosters and, and secretary-triage work } \\
\text { pairs (Extract 8). }\end{array}$ & $\begin{array}{l}\text { Communication } \\
\text { as informing } \\
\text { Communication } \\
\text { as discussion } \\
\text { Training }\end{array}$ & \\
\hline \multirow[t]{2}{*}{$\begin{array}{l}\text { Plann } \\
\text { ing } \\
\text { phase }\end{array}$} & $\begin{array}{l}\text { Five } \\
\text { planning } \\
\text { meetings } \\
\text { between } \\
17 \\
\text { September } \\
\text { and } 17 \\
\text { November } \\
2010\end{array}$ & $\begin{array}{l}\text { Planning } \\
\text { group: head } \\
\text { nurse, } \\
\text { charge } \\
\text { nurse, and } \\
\text { staff nurse }\end{array}$ & $\begin{array}{l}\text { The head nurse expresses her disappointment } \\
\text { in the staff (Extract 1), which leads to the } \\
\text { decision that the planning of the change is the } \\
\text { managers' duty. } \\
\text { Discussion of and aim to solve the problems } \\
\text { which the staff had mentioned in the first and } \\
\text { second development meetings, e.g. nursing } \\
\text { resources in the trauma room. Discussion of the } \\
\text { new care group model, and a decision to } \\
\text { implement it later than the other changes. } \\
\text { Discussion of the competencies required by the } \\
\text { work of the chief duty nurse, plus training needs } \\
\text { (Extract } 2 \text { ). Planning and preliminary decisions } \\
\text { on the duties of the chief duty nurse and on the } \\
\text { nurses who would have the competence to work } \\
\text { as chief duty nurse. Planning and preliminary } \\
\text { decisions on the new division of labour } \\
\text { between the charge nurse and the chief duty } \\
\text { nurse (Extract } 3 \text { ). Discussion of the principles } \\
\text { underlying the planning of shift rosters, with } \\
\text { preliminary decisions on new shift rosters. } \\
\text { Planning of the statutory co-determination } \\
\text { meeting, the new practice of morning meetings } \\
\text { in the clinic and allocating ample nursing } \\
\text { resources for the beginning of the } \\
\text { implementation. }\end{array}$ & $\begin{array}{l}\text { Training } \\
\text { Identity work } \\
\text { Leadership }\end{array}$ & \\
\hline & $\begin{array}{l}\text { Statutory } \\
\text { co- } \\
\text { determinat }\end{array}$ & $\begin{array}{l}\text { Nursing } \\
\text { staff (about } \\
30\end{array}$ & $\begin{array}{l}\text { The head nurse and chief physician informed the } \\
\text { staff about the changes. Participants asked } \\
\text { about the tight schedule for carrying out the } \\
\text { changes in the treatment rooms and for recruiting }\end{array}$ & $\begin{array}{l}\text { Communication } \\
\text { as informing } \\
\text { Communication } \\
\text { as discussion }\end{array}$ & \\
\hline
\end{tabular}




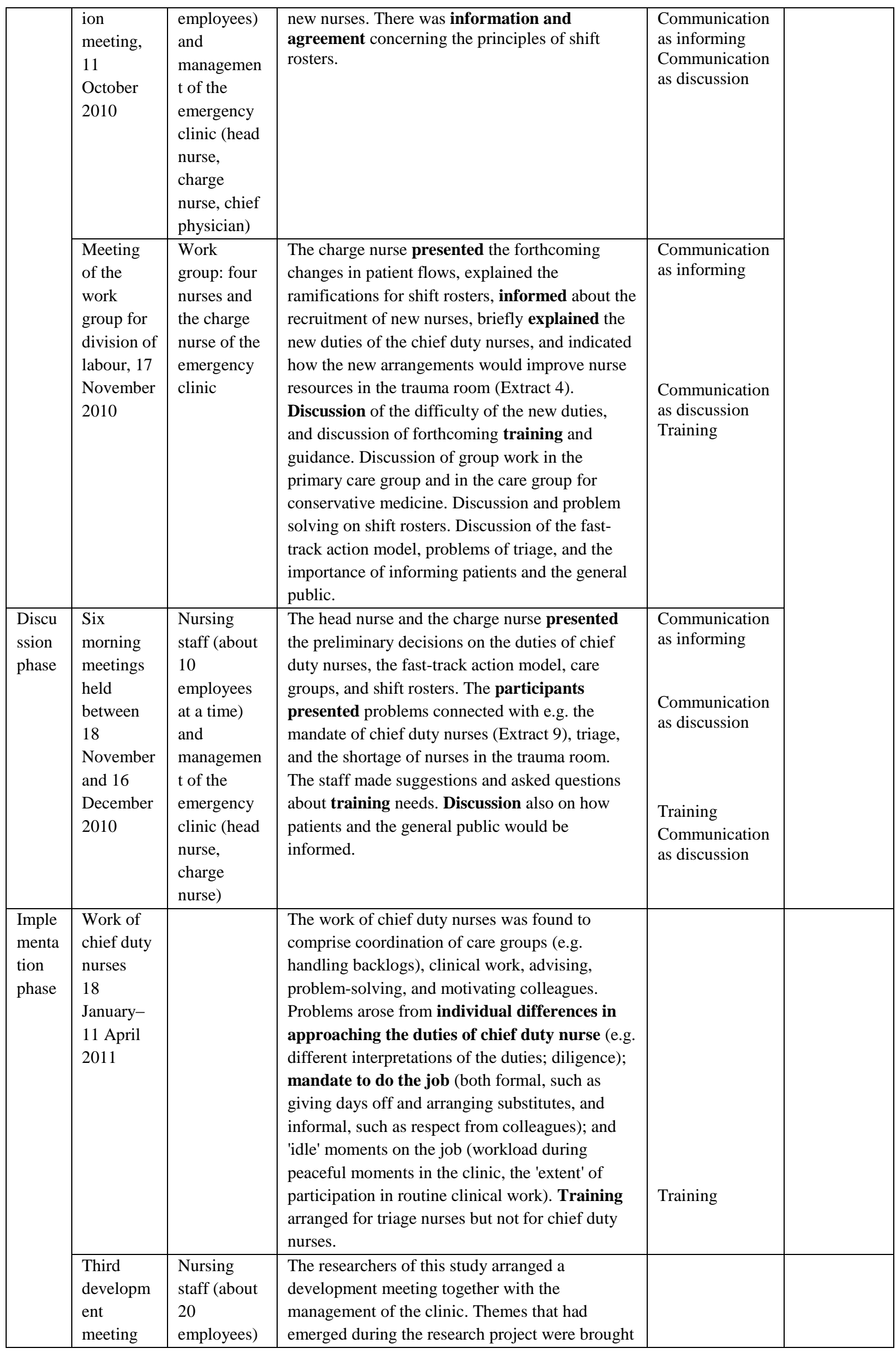




\begin{tabular}{|l|l|l|l|l|}
\hline 2011 & $\begin{array}{l}\text { and } \\
\text { managemen } \\
\text { t of the } \\
\text { clinic (head } \\
\text { nurse, } \\
\text { charge } \\
\text { nurse), as } \\
\text { well as } \\
\text { researchers }\end{array}$ & $\begin{array}{l}\text { up for general discussion by the researchers: } \\
\text { coordination of the clinic's collaboration, the new } \\
\text { chief duty nurse model, the fast track practice. } \\
\text { As for the chief duty nurse model, it was } \\
\text { generally viewed as good that there is one person } \\
\text { with an overview of the clinic's situation and who } \\
\text { can be consulted when necessary. However, one } \\
\text { surmised that the duties of the chief duty nurse } \\
\text { are not necessarily clear to all care group nurses. } \\
\text { Discussion on the chief duty nurse's participation } \\
\text { in routine clinical work. Chief duty nurses } \\
\text { experienced major simultaneous backlogs in all } \\
\text { sections of the clinic. Insufficiency experienced } \\
\text { concerning the major responsibility of chief duty } \\
\text { nurse. Training wanted e.g. on actions in early } \\
\text { stages of calamities, and collaboration with the } \\
\text { emergency ward. }\end{array}$ & Training \\
\hline
\end{tabular}

\section{Leadership, training, identity work, and communication and feedback during the change}

Leadership: In organizing the meetings and the groups in which the change was prepared, planned, and discussed, the role of the nursing managers was crucial. The head nurse's initial plan was that the new practices (and especially the new shift rosters and structures in the care groups) would be planned in the meetings attended by most of the nursing staff. However, after the second development meeting, she noticed that this would not work as she had planned. In the first planning meeting, the head nurse reflected on the discussions during the last preparation meeting.

Extract 1: First planning meeting: The head nurse reflects on the previous development meeting

I was somehow so disappointed in the group not really producing anything, since they had so much to say when we did the analysis in the spring - those four matters clearly came up. But when they had the chance to push them forward, we went backwards. But when I've thought about it afterwards, the matters might have been too difficult for the staff. Like this care group placement... maybe they can't think about it after all.

In Extract 1, the head nurse expresses her disappointment in her subordinates, since they had been unable to provide suggestions for a new care group model in the preparation meeting. This led to the decision by the head nurse that only the nursing managers of the clinic would participate in the planning meetings.

In addition to regulating the groups in which the planning and discussion of the change would take place, the managers controlled participation practices: one of the managers, usually the head nurse, acted as the chairperson in the development meetings and morning meetings. However, the employees, too, had opportunities to participate in different ways - and could also choose not to participate.

Training and support for new roles in teams: In our data, training emerged in connection with discussing about teams, contrary to previous research which has highlighted teams from the viewpoint of leadership (e.g. Edmondson et al. 2001; Ortega et al. 2013). Overall, the role of teams in the change was small, contrary to training, which was discussed in all phases of the change. For example, in the third planning meeting, the head nurse stressed the need to train nurses who would work as chief duty nurses. Training would be carried out in follow-up 
groups; these would be set up in parallel with the new duties allocated to the chief duty nurses. The head nurse repeatedly expressed her view that the chief duty nurses would need a high degree of support and training for their new duties. In Extract 2, in addition to underlining the importance of support for chief duty nurses, the head nurse sets out a plan for new work groups (which she terms follow-up groups) to evaluate and develop the new chief duty nurse model.

\section{Extract 2: Third planning meeting: The head nurse comments on support for the chief duty nurses}

This group will need a lot of support here. And I have an idea that now that we're considering, for example, this chief duty nurse model and care group planning and triage, we have to have an arrangement by which these groups have someone keeping an eye on them. Like with the nurses' practice [a section of the clinic where experienced nurses treat patients independently], we'd have a work group that meets frequently and considers how things have been running and whether something should be changed or whether training is needed. So, follow-up groups should be established for chief duty nurses, for triage nurses, and for the nurses' practice.

Extract 2 indicates that training and support would mean setting up a new group in which training would be carried out. In the morning meetings, employees also asked questions concerning training. In connection with the new fast-track action model, new training needs also emerged concerning triage nurses; this was because triage nurses would have to know which patient cases should be directed to the fast-track and which directed to follow-up primary care. At the beginning of Extract 2, the head nurse refers to the group of chief duty nurses which will need training. Thus, the head nurse sees that training needs in connection with the change only concern this one group, and not the entire staff.

All the training was planned to take place in follow-up groups, meaning teams. The training and support of nurse's practice was already continuously taking place in the clinic, and, based on our data, team training for triage nurses was also arranged. However, in the implementation phase, there was no evidence on training teams for chief duty nurses. Training needs for chief duty nurses were brought up again by staff members in the third development meeting in the implementation phase. Training arranged for the chief duty nurses might have reduced the individual differences in approaches to the role that were found in the implementation phase (see Table 2).

Identity work was interpreted from the data as a way of speaking, in which a speaker takes the position of different actors. This took place in the planning meetings when the new division of labour was discussed. In the planning group, one of the participants, the staff nurse, considered her different roles in the clinic. In so doing, she constructed new tasks, including a new role and identity, for the chief duty nurse. An example of this is presented in Extract 3.

\footnotetext{
Extract 3: Second planning group meeting: The staff nurse comments on roles and responsibilities (emphases added by the researchers)

In terms of daily issues, but also maybe in terms of more personal issues and issues related to activity in general; [I would hope that] these would be discussed first - that we would be trained to discuss with this small buffer group [of chief duty nurses] that takes matters forward. So that they [the nursing staff] would learn to have confidence that we will take matters forward. Furthermore, daily personnel management should absolutely be removed from the charge nurse's duties. Because it is so time-consuming; if I were in that role [of chief duty nurse], I'd perceive that I was [truly] in that role, that I would have ample time to do the personnel management plus the buffering.
}

The staff nurse first identifies herself as a member of the entire nursing staff when she says that nurses - including herself - should be trained to bring their concerns to the chief duty nurse ('we would be trained to discuss'). After that, she refers to the group of chief duty 
nurses of which she is also a member ('we will take matters forward'). At the end of the extract, she concludes that, as a chief duty nurse, she will have enough time to do the tasks discussed; however, at the same time, she takes the perspective of the charge nurse when she says that it is important to release the charge nurse from the daily duties of personnel management. The staff nurse here considers the role of chief duty nurse in relation to the other nursing roles: she is partly a member of the staff and partly a member of the management.

Communication and feedback: In the change process, two forms of communication were found in the data: communication as informing and communication as discussion.

Communication as informing meant managers informing the staff about the change and communication as discussion denoted two-way communication between the managers and the staff. In terms of informing, the reasons for the change (Portoghese et al. 2012) were communicated to employees in the second development meeting and in the statutory codetermination meeting. However, communication as informing was not continuous, since the planning phase lacked regular meetings open to the entire staff. The discussion phase did include communication as informing concerning the plans and decisions made in the planning group.

Extract 4 is an example of communication as informing. It contains comments by a charge nurse during a meeting of the work group on the division of labour. These concern the scheduling of the changes and nursing resources. The charge nurse justifies the extended schedule by outlining the process through which the managers were able to increase the number of new nurses, and reports how the head nurse had succeeded in persuading the hospital's finance committee to grant a sufficient number of new nursing vacancies.

Extract 4: Meeting of the work group for the division of labour: Charge nurse explains new resources

Charge nurse: To the question, 'Why has this taken so long and it's just at this stage?' I'd say, it's mid-November. A few weeks back, we were only supposed to get seven new nurses. Now it's been re-evaluated, and we've finally got the twelve we wanted. So [the head nurse] really worked hard to make this happen. You can be grateful to her that she refused to give up on this.

Nurse: Well done [head nurse]!

Charge nurse: She was really persistent and they agreed to this when she emphasized it. First, we counted [the workforce] and saw that we couldn't manage with just seven extra nurses, we needed more. However, the first outcome was that we were only promised seven new vacancies. Then, we did a test roster and saw that it wasn't enough. Personally, I'm glad that we got these twelve.

In our data we found no evidence of the resistance to change which has been observed in several previous studies (e.g. Kellogg et al. 2004; Kan and Parry 2004). However, uncertainty about whether there would in fact be enough time for the necessary changes, e. g. the spatial alterations, and whether the nursing resources would be sufficient, was presented in the statutory co-determination meeting. This led to the managers reassuring the staff that all the necessary actions will be taken on time. In Extract 4, the charge nurse's account about why the process took such a long time relates to this topic.

As for communication as discussion, it emerged in the preparation phase as dealing with problems of the clinic, namely backlogs and shortage of nurses in the trauma room. The managers took these problems seriously and, in the planning phase, aimed to solve them with the new chief duty nurse model. The problems and concerns expressed in the meetings were eventually solved during the change: when observing the implementation, we noticed that 
there were more resources to handle backlogs and the shortage of nurses in the trauma room, as the chief duty nurse now had more time to coordinate the workload.

In the change process we studied, two new arenas for communication emerged. One such arena was the morning meetings, which the planning group decided to put into action and to continue into the implementation process. The other arena was observable in the planning phase. Problems which the charge nurse had previously had to manage alone were now addressed by the planning group, working as a team. In the first two development meetings, some members of staff had expressed discontent regarding the planning of shifts, which the charge nurse was responsible for. In a discussion with the researchers, the charge nurse said that she felt that she did not receive enough support from her superiors in the difficult situations that arose with the staff. At the same time, she perceived the usefulness of joint planning and communication with the head nurse and the staff nurse, as shown in Extract 5:

Extract 5: Second planning group meeting: The charge nurse and the researchers discuss care group planning

Researcher: Have you previously planned the care groups like this? So that the head nurse participates?

Charge nurse: No! This is new and good... this is very good... we haven't. It's kind of been my responsibility.

Feedback (Baker et al. 2013) was rather rare in our data, since it only emerged in the first morning meeting. The participants discussed the new duties of the chief duty nurse and considered situations which in fact presupposed approval by the charge nurse of the chief duty nurse's decisions. During the morning meeting in question, the charge nurse gave feedback on the past actions of chief duty nurses, as presented in Extract 6.

Extract 6: First morning meeting: The charge nurse gives feedback

Not once during these six years has there been a situation where a chief duty nurse would have done something I didn't approve of. You've done the job really well.

\section{Conclusions from step one: Phases of the change and aspects of learning}

The first phase of the change, preparation, included meetings between the management and the staff of the clinic, in which the main concerns of the clinic were discussed and information about the change shared. In the planning phase, new practices, especially the duties of the chief duty nurses, were discussed and planned. The discussion and implementation phases included situations in which the plans were converted into practices (see Berends et al. 2003; Gherardi and Nicolini 2001). In the discussion phase, the aim was to arrive at a consensus (see Lines 2005) about the new chief duty nurse model and the rosters. The implementation phase also included negotiating the details of the new procedures to be followed and disseminating knowledge concerning new practices (see Berends et al. 2003). In this case it meant different views of (for example) how certain duties of the chief duty nurse should be interpreted, and what these duties might mean in practice in different kinds of situations (See Table 2).

In previous studies concerning phases of change, Dobers and Söderholm (2009) concentrated on the beginning and ending of development projects through the concepts of translation and inscription. Translation, as described by Dobers and Söderholm (2009) above, was similar to the preparation and planning phases found in this study. In the planning phase, one ended up 
with an action plan based on the expressed problems and preliminary plans. Inscription, however, was not equivalent to the discussion and implementation phases of this study, because these phases did not include reports for prospective subsequent changes. The study by Edmondson and her colleagues (2001) provided information about the phases that successful surgical teams went through. In Edmondson and colleagues' study, preparation for change was found to be important for learning new practices in the enrollment and preparation phases, which is congruent with the findings of this study. However, contrary to this study, Edmondson and colleagues (2001) studied the adoption of new surgery technology, which enabled a 'dry run' in the preparation phase, and its reflection. In the change described in this study, a dry run was not conducted. The discussion and implementation phases described in this study included similar features as the trials and reflection phases described by Edmondson and colleagues (2001). However, as the organizational change in this study encompassed the entire staff instead of one team, the discussion and implementation phases in this study included negotiating the details of the new procedures and arriving at a consensus about them.

Regarding leadership as an aspect of fostering learning amid change, it was found in this study that the managers of the clinic organized the occasions (e.g. meetings) where the change was advanced. Ortega and colleagues (2013) have found change-oriented leadership to play a crucial role in learning; however, in our data, there were no obvious links between leadership and learning opportunities. More evidently, however, the managers regulated employee participation opportunities in the different occasions connected to the change.

Training was discussed throughout the change but was only partly implemented. Our observations from the implementation phase indicate that employee participation in training was limited: training was arranged for triage nurses but not for chief duty nurses. Based on our contextual knowledge, this might be due to the clinic not having a suitable training model for the new chief duty nurse model. There were established and functional training teams for nurse's practice and triage, and these were also planned for chief duty nurses, as presented in Extract 2. However, the training models presupposed experiential knowledge and expertise over a longer period from those nurses who were responsible for the training teams. In terms of chief duty nurses, this was not possible, because it was a recently established practice. Aside from these training teams, teamwork was not essential in the change. The reason for this might be the continuous change in the composition of care groups, which was typical for the clinic in question (see Collin et al. 2012). Were the teams more permanent in nature, their role and leadership might have been more central to the change, as found by Edmondson and colleagues (2001).

In the third development meeting in the implementation phase, the participating chief duty nurses expressed insufficiencies concerning the major responsibilities of the chief duty nurse. Training arranged for chief duty nurses might have helped combat these experiences of insufficiency. Training might also have helped level the individual differences in approaching the role of chief duty nurse that were found in the implementation phase (see Table 2). Had there been training, individual opportunities for the learning of new practices would have been stronger, as found by Conceição and Altman (2011). Even though the individuals in question experienced insufficiency, based on our observations, the chief duty nurses were able to manage quite well in their new role.

In this case study, planning and decision-making on new roles included a way of speaking that we interpreted as identity work. However, this only concerned one employee in the 
planning group, as employee participation in the planning phase was limited. Nevertheless, identity work in the form of the creation of new roles and knowledge would indeed have been fruitful for individuals (see Gherardi and Nicolini 2001). As illustrated by the staff nurse's contribution in Extract 3, the multiplicity of positions taken by the staff nurse and their expression in group discussions did have the potential to facilitate new roles and identities. Previous studies have suggested that identity work is important for individual employees' well-being (Vähäsantanen 2013) and for learning opportunities amid change (Miller et al. 2000). We conclude that this was the case in our study as well, at least for one of the participants in the planning group. Identity work would also have been beneficial for employees' learning opportunities more broadly; for example, it would have allowed chief duty nurses to consider their new role and identity.

Communication: As noted, there was no evidence of resistance to change among the staff. The reason for this might be that communication about the reasons for the change was sufficient, the staff was provided with opportunities to present their concerns, and the managers took these concerns seriously. Additionally, Miller and colleagues (Miller et al. 2000; Miller and Apker 2002) have found frequent communication between the management and the staff to be important in adaptation to change. In addition to sufficient amount of communication, the nature of communication has also been noted as being important by previous studies that have emphasized a confidential and psychologically safe communication environment as favourable for learning amid change (Gubbins and MacCurtain 2008; Edmondson et al. 2001; Eteläpelto and Lahti 2008; Bunderson and Boumgarden 2010). In this study, managers have tried to generate confidence by offering disclosure of information about changes, e.g. the above-mentioned reassurance about the time schedule, and taking the staff's concerns seriously.

Within the change, two new arenas for communication emerged: the morning meetings and the collaborative planning of shift rosters. During organizational change, it may be more necessary than in regular organizational life to generate more effective ways of communicating (see Bess et al. 2011). Edmondson and colleagues (2001) have found that, in successful teams, communication increased during the learning of new surgical technology. In this study as well, communication was found to increase during the change. In so far as learning is viewed as occurring within interaction and within social workplace activities (Brown and Duguid 1991; Easterby-Smith et al. 2000), new arenas for communication of this kind also create learning opportunities - just so long as they include opportunities for employee participation.

Participation was found to be a connective aspect of the other aspects described above. In terms of leadership, the managers played an important role in promoting or hindering employee participation in the different phases of the change. With regard to training, it was found that employee participation in training was limited as training was not available for the entire staff in the change. One can speculate that identity work might have been possible more broadly if employee participation had been feasible in the planning of the new roles and duties of chief duty nurses. At the same time, new arenas for communication meant new opportunities for participation. From this, we interpret participation as a connective element of leadership, training, identity work, and communication. Participation was a recurring element throughout the change, unlike the other aspects of learning in change presented above. Different staff members had differing opportunities to participate during the change, and that the nature of individuals' participation also varied. 


\section{Focusing on the research objective: the research questions}

In previous studies, employee participation in organizational processes and decisions has been found to be very closely connected to learning in organizations (Bess et al. 2011; Gherardi and Nicolini 2001; López et al. 2006), and this also applies during organizational change (Easterby-Smith et al. 2000; Lines 2005). Participation in an organization is defined as 'a style of working whereby organizational members from different functions and hierarchical levels work together in order to develop and implement a solution to an organizational problem' (Lines 2005, 158-159). Employee participation has been viewed as enhancing organizational learning, since it gathers together employees who have different kinds of experience, skills, and knowledge (Kitzmiller et al. 2010). This allows them to provide diverse information for reflection and decision-making processes, and these in turn generate multiple interpretations and opportunities to create new meanings and solutions (Ashmos et al. 1998). If team members have different kinds of experience, skills, and knowledge, they can contribute by predicting the consequences of planned changes and, overall, provide the planning team with new information (Ashmos et al. 1998). Participatory decision-making also empowers members, providing them with the responsibility and resources to make work-related decisions (Bess et al. 2011). Learning through participation is possible if an organization has practices and structural mechanisms in place for joint decision-making and collective reflection (Bess et al. 2011). Participation tends to occur in organizations which place a high value on rich connections among organizational members (Ashmos et al. 1998). However, previous research has, generally speaking, not paid much attention to the various aspects of employee participation in connection with organizational changes (Sverke et al. 2008) and learning.

On the basis of our findings from the first step and from previous studies, we focused the research objective more narrowly, asking the following questions:

1. What kinds of participation opportunities were available and what was the nature of employee participation in the different phases of the change?

\section{What kinds of learning opportunities were facilitated by the opportunities for} participation, and by the nature of the participation in question?

In this study, the participation opportunities consisted of structures for participation and practices for participation. Structures for participation denote work groups or regular meetings, whereas practices for participation are seen as the actions and practices of a group or a meeting that facilitate participation (see Bess et al. 2011); these include the ways of interacting that enable employees to contribute to decision-making, and which facilitate collaborative processes and the communication of decisions across the organization (Bess et al. 2011).

Participation opportunities are something that an organization provides for its employees (see Billett 2002). The nature of participation - how actively individuals actually utilize the participation opportunities provided (see Billett 2002) - was explored in this study through the concepts of weak and strong participation (Lines et al. 2005). Weak participation is operationalized as receiving information, a question-answer type of interaction, and the expression of problems; by contrast, strong participation refers to individuals' more active 
way to participate, in this case, problem-solving, suggestions and decisions concerning new practices, and identity work.

\section{Analysis, step two}

We categorized the meetings and the interaction in them according to the operationalizations of participation opportunities and the nature of participation, as mentioned above (see Hsieh and Shannon 2005). Whether there were structures of participation was inferred on the basis of our observations of the work groups and meetings in the clinic, and our contextual knowledge of who were invited to the meetings, e.g. only managers or also staff. As for practices of participation, the findings are based on the coding of the brief summaries and the chronology of the meetings. The coding is presented in Appendix 2.

We concentrated on the first three phases of the change, and the data concerning the implementation phase were used to validate our data from the first three phases of the change. The findings regarding the first research question are presented in the following section. The second research question is examined through the conclusions and interpretations of the findings derived from the first research question.

\section{Findings, step two: Participation opportunities and the nature of participation amid change}

Table 3. Participation opportunities and the nature of participation in the various phases of the change 


\begin{tabular}{|c|c|c|c|c|}
\hline \multirow[b]{2}{*}{ Phase } & \multicolumn{2}{|c|}{$\begin{array}{l}\text { Participation opportunities provided in } \\
\text { the organization }\end{array}$} & \multicolumn{2}{|c|}{ Nature of employee participation } \\
\hline & $\begin{array}{l}\text { Structures } \\
\text { facilitating } \\
\text { employee } \\
\text { participation }\end{array}$ & $\begin{array}{l}\text { Practices } \\
\text { facilitating } \\
\text { employee } \\
\text { participation }\end{array}$ & Weak & Strong \\
\hline Preparation & $\begin{array}{l}\text { Yes: meetings were } \\
\text { open to the staff. }\end{array}$ & $\begin{array}{l}\text { Yes: meetings } \\
\text { included general } \\
\text { discussion and } \\
\text { group work (Extract } \\
\text { 7). }\end{array}$ & $\begin{array}{l}\text { Question-answer } \\
\text { manner of } \\
\text { interacting. } \\
\text { Receiving } \\
\text { information. } \\
\text { Expressing } \\
\text { problems (Extract } \\
\text { 7). }\end{array}$ & $\begin{array}{l}\text { Suggestions for new practices } \\
\text { (Extract } 8) \text {. }\end{array}$ \\
\hline $\begin{array}{l}\text { Planning phase: } \\
\text { Planning meetings }\end{array}$ & $\begin{array}{l}\text { No: only managers } \\
\text { participated. }\end{array}$ & $\begin{array}{l}\text { No: only managers } \\
\text { participated. }\end{array}$ & & $\begin{array}{l}\text { Nature of managers' } \\
\text { participation: Identity work } \\
\text { and mutual decisions on new } \\
\text { practices (Extract } 3 \text { ). }\end{array}$ \\
\hline $\begin{array}{l}\text { Planning phase: } \\
\text { statutory co- } \\
\text { determination } \\
\text { meeting }\end{array}$ & $\begin{array}{l}\text { Yes: the meeting } \\
\text { was open to the } \\
\text { staff. Statutory basis } \\
\text { for inviting the } \\
\text { entire staff. }\end{array}$ & $\begin{array}{l}\text { No: the meeting did } \\
\text { not have an effect } \\
\text { on the decisions of } \\
\text { the planning group. }\end{array}$ & $\begin{array}{l}\text { Receiving } \\
\text { information. } \\
\text { Question-answer } \\
\text { manner of } \\
\text { interacting. } \\
\text { Expressing } \\
\text { problems. } \\
\end{array}$ & \\
\hline $\begin{array}{l}\text { Planning phase: } \\
\text { meeting of work } \\
\text { group for the } \\
\text { division of labour }\end{array}$ & $\begin{array}{l}\text { Yes: for a selected } \\
\text { group of employees. }\end{array}$ & $\begin{array}{l}\text { No: the meeting did } \\
\text { not have an effect } \\
\text { on the decisions of } \\
\text { the planning group. }\end{array}$ & $\begin{array}{l}\text { Receiving } \\
\text { information. } \\
\text { (Extract 4). } \\
\text { Expressing } \\
\text { problems. }\end{array}$ & Problem-solving \\
\hline Discussion & $\begin{array}{l}\text { Yes: regular } \\
\text { meetings. Six } \\
\text { meetings } \rightarrow \text { the } \\
\text { entire staff were } \\
\text { able to participate, } \\
\text { taking turns. }\end{array}$ & $\begin{array}{l}\text { Yes: the decisions } \\
\text { were presented as } \\
\text { preliminary } \\
\text { suggestions and } \\
\text { discussion was } \\
\text { encouraged. }\end{array}$ & $\begin{array}{l}\text { Receiving } \\
\text { information. } \\
\text { Expressing } \\
\text { problems (Extract } \\
\text { 9). }\end{array}$ & $\begin{array}{l}\text { Suggestions for new practices } \\
\text { (Extract 9) }\end{array}$ \\
\hline
\end{tabular}

\section{Preparation phase}

As can be seen in Table 3, the preparation phase included both structures and practices pertaining to employee participation. This means that there were groups and meetings available that would allow people to prepare for the change; these involved participatory practices, for instance, open discussion. The employee participation in the general discussions was weak, consisting of informing, question-answer interaction, and the expression of problems. In the preparation phase, the staff discussed the problems of the emergency clinic, the shortage of personnel in the trauma room, and backlogs. In the planning phase, the planning group also addressed those matters which could be improved by a new distribution of work and by developing the duties of the chief duty nurse. In Extract 7, two nurses express their concern over the shortage of nurses in the trauma room.

\section{Extract 7: First development meeting: Nurses express concern}

Nurse 1: In the morning shift, it was peaceful. On Tuesday, [there were] seven patients during the evening, one resuscitation, and one new employee undergoing orientation. 
Nurse 2: This morning was similar: one died, five survived. And there are still two left. So, what can we do to secure our safety, our own and that of our patients? No one will sit in court on our behalf, we've seen and heard it before, so it's our safety and the patients' safety.

Concern over the trauma room was also expressed by the employees in subsequent phases of the change. In the planning meetings, the nursing managers presented different solutions to the problem, aiming to solve it by modifying the chief duty nurse model. The issue was also discussed in most of the morning meetings. Finally, in the implementation phase, we observed how the chief duty nurses actually worked out a solution to the problem; this involved organizing extra resources for the trauma room by asking a nurse from one of the care groups to assist.

The second development meeting also included small-group work, in which new practices were discussed. In fact, the initiative and idea for reconsidering the duties and arrangements of the chief duty nurses came from employees in the second development meeting. Aside from this, some suggestions for new practices also emerged in the general discussions, as illustrated in Extract 8.

\section{Extract 8: Second development meeting: A nurse suggests a new practice}

Could we have like an education pathway or something, because now, I think triage is ok and I can do it, but being a chief duty nurse? No way. A sort of education pathway in which you could proceed...

Here, a nurse suggests having a training pathway for nurses who want to learn new duties. If the duties of the triage nurse and chief duty nurse were distinct, it would be easier for her and for newcomers to take up those duties: they could proceed step by step, first taking on the duties of the triage nurse and thereafter those of the chief duty nurse. These kinds of contributions were interpreted as strong participation.

\section{Planning phase}

Participation in the planning phase was restricted, in the sense that only three nurse managers participated: the head nurse, the charge nurse, and the staff nurse. There were no participatory practices involving staff in the planning phase, although the course of the process would have allowed participation, bearing in mind that the co-determination meeting actually occurred before the last planning meeting. However, in the last planning meeting, there were no references to the discussions of the co-determination meeting, and hence that meeting appeared to escape notice in the planning group. In addition to the co-determination meeting, another possible structural forum for participatory planning and decision-making would have been the 'work group for the division of labour'. This group was managed by the charge nurse, and comprised four experienced nurses. However, the role of the group was somewhat marginal, since it did not attend the planning or decision-making processes and instead discussed plans which had already been made by the planning group.

Manager participation in the planning group was strong, given that all the members of the group took part in the decision-making. The staff nurse worked as a nursing practitioner alongside her staff nurse duties, unlike the head nurse and the charge nurse. She had an active role in the discussions and decisions of the planning group, and fairly frequently expressed the viewpoints of the nursing personnel in the clinic. On several occasions, she positioned herself as a member of the nursing staff. Extract 3 (see above) shows one of the staff nurse's contributions in planning the duties of the chief duty nurse. 
The discussions of the work group for the division of labour exhibited strong participation in problem-solving. However, it remained marginal in the change, since the discussions of the work group for the division of labour did not have an effect on organization-level decisions, and only a few employees participated in the group.

\title{
Discussion phase
}

Because employees worked in three shifts, it was impossible to gather the entire staff in any one meeting to give information and discuss the new chief duty nurse model. For this reason, several morning meetings were arranged in which the staff could comment on the plans and reflect on their implementation. The morning meetings provided structures facilitating employee participation. Participatory practices emerged in the discussion phase of the process.

The managers emphasized that the plans they had made during the planning phase were still proposals, which the staff could comment on and which could be changed on the basis of discussion, reflection, and experiences with practical trials. Extract 9 illustrates weak participation in the form of expressing problems and strong participation in the form of a suggestion for a new practice, here concerning the chief duty nurses' mandate to organize substitutes for sick leaves.

\section{Extract 9: One of the morning meetings: The nurses discuss sick leaves}

\begin{abstract}
Nurse 1: About short sick leaves once more, since you said that we've managed so far. Sure, we can handle one evening shift, but the next ones - the charge nurse has had to take care of those because she has the right to alter shift rosters and give days off, which we can't do. That's how we've managed up until now. Weekdays and weekend. And we've had to call a bunch of people numerous times.
\end{abstract}

\begin{abstract}
Head nurse: Um, the main principle is that we continue with the same chief duty nurses as before. And the charge nurse wants to have discussions with these nurses about the new tasks. And the fact is that the charge nurse is in his/her office, or out and about. So, first, you try to resolve the matter and, if you can't, then of course you go to the charge nurse or the staff nurse and say that you have such and such arrangement... but this presupposes that days off can be given.
\end{abstract}

Nurse 1: Yes, and we don't have the right to give days off..

\section{$[\ldots]$}

Nurse 1: And there's a lot in it when you think about it - there seems to be these sick leaves all the time, we're short of staff all the time... so the chief duty nurse has a lot to do, for example, if five people are off sick at the same time.

Head nurse: When that happens, the superior will step in to help, I'm sure. But you should try to start on
your own. Nurse 1: Yes... but since we're used to doing the task at hand properly... there's a lot to do, really.

Nurse 2: If only we could give days off, e.g. if someone promised to take an evening shift if they got a day off the following week. If only we could promise that it would be okay.

Head nurse: I'll take it up now, I see that it'd be sensible if the chief duty nurse had the mandate to give days off. I can't speak for your immediate superior on this matter right now, so we'll have to think about it first, about what the terms would be if this practice were possible. Because it would facilitate [the shift] planning.

The participants comment that it is a problem that only the charge nurse has the right to give days off. This leads to a discussion on the chief duty nurse's rights and mandate to organize 
substitutes for sick employees as a suggestion for a new practice. Finally, the head nurse indicates that she will reconsider the matter.

\section{Conclusions: Learning opportunities provided by participation during the change}

The aim of this study was to examine learning opportunities amid a process of organizational change. The study confirmed the importance of participation within such a process.

Previously, participation has been defined as employees' participation in problem-solving and decision-making in the organization (Lines 2005; Bess et al. 2011). However, in this study, participation manifested itself as a more multifaceted phenomenon than what has emerged in previous studies such as López et al. (2006), Bess et al. (2011), Sverke et al. (2008), and Lines (2005). In this study, employee participation in the change was delineated by connections between organizational and individual levels, namely, i) structures and practices facilitating employee participation, provided by the organization, and ii) nature of participation within these structures and practices, chosen by individual employees. Further, the multifaceted nature of participation manifested itself in our findings concerning employee problem-solving and decision-making, which previous studies have defined as employee participation. As for problem-solving, even though the nature of individual-level participation was strong, organization-level participation practices hindered the problem-solving from influencing the change. Employee decision-making was not found in this study, because the plans and decisions concerning the change were made in the managers' planning group. Further, aspects that have not been connected to employee participation in previous studies, namely, expression of problems and suggestions for new practices, were found to be important in terms of employee participation in the change explored in this study. These individual-level activities had an influence in the change, because organization-level structures and practices enabled this.

Furthermore, in previous studies (López et al. 2006; Bess et al. 2011; Lines 2005), employee participation opportunities have been found to be connected to learning in the organization. In this study, structures and practices facilitating participation were prerequisites for participation by individual employees. As employee participation was not made structurally possible throughout the planning phase of the change, the employees did not have opportunities for strong participation, particularly in terms of identity work. In the present study, identity work was manifested in a small-group discussion in the planning phase, in which new roles and practices were created. We conclude that a small group of participants provided a suitable forum for identity work and discussion. If these kinds of participation opportunities had been available more broadly, there would have been better individual-level learning opportunities for the people in question, particularly the chief duty nurses who were at the hub of the change. At the same time, opportunities for training were restricted, as found in the first step of the study. To sum up conclusions from Steps One and Two, critical points in terms of individual-level learning opportunities in the organizational change were participation opportunities for the staff in i) planning and decision-making, ii) identity work, and iii) training before and during the implementation of new practices. These did not sufficiently materialize in this case, and we suggest that these aspects require more attention in terms of executing organizational changes and organizational development.

Although employees were not included in the decision-making in the planning phase in this study, employee participation increased organization-level learning opportunities, particularly in the preparation and discussion phases of the change, in the form of expressing 
problems. The most prominent of the problems expressed were the shortage of nurses in the trauma room and suggestions for new practices, e.g. modifications to the chief duty nurse model. Organization-level learning opportunities were increased when the problems and developmental ideas, observed by employees were heard and taken into consideration by the managers in developing the clinic's practices. Thus, in the present case study, suggestions for new practices by employees led to changes in organizational roles, knowledge, and practices (see Gherardi and Nicolini 2001) and hence in organization-level learning opportunities. On the other hand, strong employee participation in the form of problem-solving did not play a role in organization-level learning opportunities in the change, as organization-level participation practices did not enable this (problem-solving took place in a working group that did not have an influence on the decision-making), and the organization-level working practices in question did not change.

\section{Credibility of the study and suggestions for further research}

This study has several limitations. A full ethnographic methodology would have required more intensive member involvement and member checking during the analysis (Lincoln and Guba 1985). However, this was prevented by major changes in the management of the clinic immediately after the organizational changes were implemented. In addition, more long-term follow-up data would have been valuable in confirming our findings concerning the practices that had been put into effect. As the researchers attended the meetings, it is possible that their presence influenced the data (Patton 2002). However, we view that, in the first three phases of the change, the influence was minor, as the participants of the study had already grown accustomed to the researchers' presence. In the implementation phase, however, the influence was more substantial due to the development meeting arranged by the researchers as part of the research and development project.

Here, it should further be pointed out that a case study approach does not allow generalizations, but that it may indicate new aspects of the phenomenon investigated, as our study aimed to do. An additional point to note is that, in seeking to validate the data in this study, both researcher and methodological triangulation were used. Despite this, a degree of subjectivity will always enter into the observations and interpretations made in qualitative research.

This study provided new knowledge on employee participation and its manifestations in micro-level interaction, as well as on both individual and organization-level learning opportunities in organizational change. We suggest that this kind of close and phase-specific scrutiny of employee participation opportunities can give detailed information to an organization on how to improve these opportunities and, hence, improve opportunities for learning. Complex and multidirectional change processes may include different lines and phases which also present different opportunities for employee participation. Hence, a single overall picture of participation could be too general and give too positive an image, if participation is not possible at those junctures in the process where the most important plans and decisions are made. Considering organizational change as a process involving discrete phases could also help managers and organizations to plan and control change processes. Different phases of change require different types of attention to be carried out successfully and prevent difficulties (Szulanski 2000), and, as in this study, facilitate employee participation and learning opportunities. 
We suggest that employee participation should be considered as a multifaceted and contextspecific phenomenon, and it should be investigated in different kinds of change situations and processes. Moreover, due to the multifaceted nature of participation, its role in learning should be explored in different kinds of organizational contexts and situations. Further research also needs to be done on the connective links between individual-level and organization-level learning.

\section{Acknowledgements}

This work was supported by the Finnish Work Environment Fund (project number 109295). 


\section{References}

Argyris, C., \& Schön, D. A. (1996). Organizational learning II. Theory, method, and practice. Reading, MA: Addison-Wesley.

Ashmos, D. P., Huonker, J. W., \& McDaniel, R. R. (1998). Participation as a complicating mechanism: the effect of clinical professional and middle manager participation on hospital performance. Health Care Management Review, 23(4), 7-20.

Baker, A., Perreault, D., Reid, A., \& Blanchard, C. M. (2013). Feedback and Organizations: Feedback is Good, Feedback-Friendly Culture is Better. Canadian Psychology, 54(4), 260268.

Bate, P. (2000). Changing the culture of hospital: from hierarchy to networked community. Public Administration, 78(3), 485-512.

Berends, H., Boersma, K., \& Weggman, M. (2003). The structuration of organizational learning. Human Relations, 56(9), 1035-1056.

Bernstrøm, V. H., \& Kjekshus, L. E. (2012). Leading during change: the effects of leader behavior on sickness absence in a Norwegian health trust. BMC Public Health, 12, 799-812.

Bess, K. D., Perkins, D. D., Cooper, D. G., \& Jones, D. L. (2011). A heuristic framework for understanding the role of participatory decision making in community-based non-profits. American Journal of Community Psychology, 47(3/4), 236-252.

Billett, S. (2002). Critiquing workplace learning discourses: Participation and continuity at work. Studies in the Education of Adults, 34(1), 56-68.

Billett, S. (2004). Learning through work: workplace participatory practices. In H. Rainbird, A. Fuller \& A. Munro (Eds.), Workplace Learning in Context (pp. 109-125). London: Routledge.

Billett, S., \& Somerville, M. (2004). Transformations at work: identity and learning. Studies in Continuing Education, 26(2), 309-326.

Bjerregaard, T. (2011). Studying institutional work in institutions. Uses and implications of ethnographic methodologies. Journal of Organizational Change, 24(1), 51-64.

Braun, V., \& Clarke, V. (2006). Using thematic analysis in psychology. Qualitative Research in Psychology, 3(2), 77-101.

Brewer, J. (2000). Ethnography. Buckingham: Open University Press.

Brown, J. S., \& Duguid, P. (1991). Organizational Learning and Communities-of-Practice: Toward a Unified View of Working, Learning, and Innovation. Organization Science, 2(1), $40-57$. 
Bunderson, J. S., \& Boumgarden, P. (2010). Structure and learning in self-managed teams: why "bureaucratic" teams can be better learners. Organization Science, 21(3), 609-624.

Bunniss, S., \& Kelly, D. R. (2008). 'The unknown becomes the known': collective learning and change in primary care teams. Medical Education, 42(12), 1185-1194.

Burke, W. W. (2008). Organization change. Theory and practice. $2^{\text {nd }}$ ed. Thousand Oaks: Sage.

Chih, W. W., Yang, F., \& Chang, C. (2012). The study of the antecedents and outcomes of attitude toward organizational change. Public Personnel Management, 41(4), 597-617.

Choi, S., Holmberg, I., Löwstedt, J., \& Brommels, M. (2011). Executive management in radical change - The case of the Karolinska University Hospital merger. Scandinavian Journal of Management, 27, 11-23.

Collin, K. (2002). Development Engineers' Conceptions of Learning at Work. Studies in Continuing Education, 24(2), 133-152.

Collin, K., \& Paloniemi, S. (2008). Supporting experience sharing as participatory workplace practice. In S. Billett, C. Harteis \& A. Eteläpelto (Eds.), Emerging Perspectives of Workplace Learning (pp. 23-35). Rotterdam: Sense.

Collin, K., Valleala, U. M., Herranen, S., \& Paloniemi, S. (2012). Ways of Interprofessional Collaboration and Learning in Emergency Work. Studies in Continuing Education, 34(3), 281-300.

Conceição, S. C. O., \& Altman, B. A. (2011). Training and Development Process and Organizational Culture Change. Organization Development Journal, 29(1), 33-43.

Dobers, P., \& Söderholm, A. (2009). Translation and inscription in development projects. Understanding environmental and health care-related organizational change. Journal of Organizational Change Management, 22(5), 480-493.

Easterby-Smith, M., Crossan, M., \& Nicolini, D. (2000). Organizational learning: debates past, present and future. Journal of Management Studies, 37(6), 783-796.

Edmondson, A. C., Bohmer, R., \& Pisano, G. P. (2001). Disrupted Routines: Team Learning and New Technology Adaptation. Administrative Science Quarterly, 46(4), 685-716.

Engeström, Y., \& Middleton, D. (1996). Introduction: Studying Work as Mindful Practice. In Y. Engeström \& D. Middleton (Eds.), Cognition and Communication at Work (pp. 1-14). Cambridge: Cambridge University Press.

Eteläpelto, A., \& Lahti, J. (2008). The resources and obstacles of creative collaboration in a long-term learning community. Thinking Skills and Creativity, 3(3), 226-240.

Fine, G. A., Morrill, C., \& Surianarain, S. (2009). Ethnography in organizational settings. In D. A. Buchanan \& A. Bryman (Eds.), The SAGE Handbook of Organizational Research Methods (pp. 602-619). London: Sage. 
Gherardi, S., \& Nicolini, D. (2001). The sociological foundations of organizational learning. In M. Dierkes, A. Berthoin Antal, J. Child \& I. Nonaka (Eds.), Handbook of Organizational Learning and Knowledge (pp. 35-60). Oxford: Oxford University Press.

Gordon, T., Hynninen, P., Lahelma, E., Metso, T., Palmu, T., \& Tolonen, T. (2006). Collective ethnography, joint experiences and individual pathways. Nordisk Pedagogik [Journal of Nordic Educational Research], 26(1), 3-15.

Gubbins, C., \& MacCurtain, S. (2008). Understanding the dynamics of collective learning: the role of trust and social capital. Advances in Developing Human Resources, 10(4), 578599.

Hager, P., Lee, A., \& Reich, A. (2012) (Eds.). Practice, Learning and Change. PracticeTheory Perspectives on Professional Learning. Dordrecht: Springer.

Hsieh, H-F., \& Shannon, S. E. (2005). Three approaches to qualitative content analysis. Qualitative Health Research, 15(9), 1277-1288.

Järvinen, A., \& Poikela, E. (2001). Modelling Reflective and Contextual Learning at Work. The Journal of Workplace Learning, 13(7/8), 282-289.

Kan, M. M., \& Parry, K. W. (2004). Identifying paradox: A grounded theory of leadership in overcoming resistance to change. The Leadership Quarterly, 15(4), 467-491.

Kellogg, K. C., Breen, E., Ferzoco, S. J., Zinner, M. J., \& Ashley, S. A. (2004). Resistance to Change in Surgical Residency: An Ethnographic Study of Work Hours Reform. Journal of the American College of Surgeons, 202(4), 630-636.

Kitson, A. L. (2009). The need for systems change: reflections on knowledge translation and organizational change. Journal of Advanced Nursing, 65(1), 217-228.

Kitzmiller, R. R., Anderson, R. A., \& McDaniel, R. R. (2010). Making sense of health information technology implementation: A qualitative study protocol. Implementation Science, 5(95), 95-103.

Lave, J. (1993). The practice of learning. In S. Chaiklin \& J. Lave (Eds.), Understanding practice. Perspectives on activity and context (pp. 3-13). Cambridge: Cambridge University Press.

Lincoln, Y. S., \& Guba, E. G. (1985). Naturalistic inquiry. Beverly Hills: Sage.

Lines, R. (2005). How social accounts and participation during change affect organizational learning. Journal of Workplace Learning, 17(3), 157-177.

Lines, R., Selart, M., Espedal, B., \& Johansen, S. T. (2005). The production of trust during organizational change. Journal of Change Management, 5(2), 221-245.

López, S. P., Peón, J. M., \& Ordás, C. J. (2006). Human Resource Management as a Determining Factor in Organizational Learning. Management Learning, 37(2), 215-239. 
Miller, K., \& Apker, J. (2002). On the front lines of managed care: Professional changes and communicative dilemmas of hospital nurses. Nursing Outlook, 50(4), 154-159.

Miller, K., Joseph, L., \& Apker, J. (2000). Strategic ambiguity in the role development process. Journal of Applied Communication Research, 28(3), 193-214.

Munroe, D. J., Kaza, P. L., \& Howard, D. (2011). Culture-Change Training: Nursing Facility Staff Perceptions of Culture Change. Geriatric Nursing, 32(6), 400-407.

Nicolini, D., \& Meznar, M. B. (1995). The social construction of organizational learning: Conceptual practices and practical issues in the field. Human Relations, 48(7), 727-746.

Ortega, A., Van Den Bossche, P., Sánchez-Manzanares, M., Rico, R., \& Gil, F. (2013). The Influence of Change-Oriented Leadership and Psychological Safety on Team Learning in Healthcare Teams. Journal of Business and Psychology. DOI: 10.1007/s10869-013-9315-8

Paloniemi, S., \& Collin, K. (2010). Mitä ihmettä on kollektiivinen etnografia? Kokemuksia organisaatiotutkimuksesta [What is collective ethnography? Experiences of organizational research]. In J. Aaltola \& R. Valli (Eds.), Ikkunoita tutkimusmetodeihin II [Windows into research methods] (pp. 204-221). Jyväskylä: PS-kustannus.

Patton, M. Q. (2002). Qualitative Research \& Evaluation Methods. $3^{\text {rd }}$ ed. Thousand Oaks: Sage.

Poell, R. F., \& Van der Krogt, F. J. (2010). Individual learning paths of employees in the context of social networks. In S. Billett (Ed.), Learning through practice. Models, traditions, orientations and approaches (pp. 197-221). New York: Springer.

Portoghese, I., Galletta, M., Battistelli, A., Saiani, A., Penna, M. P., \& Allegrini, E. (2012). Change-related expectations and commitment to change of nurses: the role of leadership and communication. Journal of Nursing Management, 20(5), 582-591.

Radley, A., \& Chamberlain, K. (2012). The Study of the Case: Conceptualising Case Study Research. Journal of Community and Applied Social Psychology, 22(5), 390-399.

Stenner, K., \& Courtenay, M. (2008). The role of inter-professional relationships and support for nurse prescribing in acute and chronic pain. Journal of Advanced Nursing, 63(3), 276283.

Suddaby, R., \& Greenwood, R. (2009). Methodological issues in researching institutional change. In D. A. Buchanan \& A. Bryman (Eds.), The SAGE Handbook of Organizational Research Methods (pp. 176-195). London: Sage.

Sverke, M., Hellgren, J., Näswall, K., Göransson, S., \& Öhrming, J. (2008). Employee Participation in Organizational Change: Investigating the Effects of Proactive vs. Reactive Implementation of Downsizing in Swedish Hospitals. Zeitschrift für Personalforschung [German Journal of Research in Human Resource Management], 22(2), 111-129. 
Szulanski, G. (2000). The process of knowledge transfer: a diachronic analysis of stickiness. Organizational Behavior and Human Decision Processes, 82(1), 9-27.

Thomas, R., \& Hardy, C. (2011). Reframing resistance to organizational change. Scandinavian Journal of Management, 27(3), 322-331.

Tsoukas, H. (2009). A dialogical approach to the creation of new knowledge in organizations. Organization Science, 20(6), 941-957.

Tsoukas, H., \& Chia, R. (2002). On organizational becoming: rethinking organizational change. Organization Science, 13(5), 567-582.

Tucker, A. L., \& Edmondson, A. C. (2003). Why hospitals don't learn from failures: organizational and psychological dynamics that inhibit system change. California Management Review, 45(2), 54-72.

Tucker, A. L., Nembhard, I. M., \& Edmondson, A. C. (2007). Implementing New Practices: An Empirical Study of Organizational Learning in Hospital Intensive Care Units. Management Science, 53(6), 894-907.

Vähäsantanen, K. (2013). Vocational teachers' professional agency in the stream of change. Jyväskylä Studies in Education, Psychology and Social Research 460. University of Jyväskylä.

Watkins, K. E., \& Marsick, V. J. (1992). Towards a theory of informal and incidental learning in organizations. International Journal of Lifelong Education, 11(4), 287-300.

Wenger, E. (1998). Communities of Practice: Learning, Meaning, and Identity. Cambridge: Cambridge University Press.

Woods, P., Boyle, M., Jeffrey, B., \& Troman, G. (2000). A research team in ethnography. International Journal of Qualitative Studies in Education, 13(1), 85-98.

Yin, R. K. (1994). Case study research: Design and methods. $2^{\text {nd }}$ ed. Beverly Hills: Sage. 
Appendix 1. An example of the first and second coding of the data

\begin{tabular}{|c|c|c|}
\hline $\begin{array}{l}\text { Sample extract from the original data (third planning } \\
\text { meeting) }\end{array}$ & First coding (data-driven) & $\begin{array}{l}\text { Second coding } \\
\text { (theory-driven) }\end{array}$ \\
\hline $\begin{array}{l}\text { Head nurse: This group will need a lot of support here. And I have } \\
\text { an idea that now that we're considering, for example, this chief } \\
\text { duty nurse model and care group planning and triage, we have to } \\
\text { have an arrangement where these groups have someone keeping an } \\
\text { eye on them. Like with the nurses' practice [a section of the clinic } \\
\text { where experienced nurses treat patients independently] now, we'd } \\
\text { have a work group that meets frequently and considers how things } \\
\text { have been running and whether something should be changed, } \\
\text { whether training is needed. So, follow-up groups should be } \\
\text { established for chief duty nurses, for triage nurses, and for the } \\
\text { nurses' practice. } \\
\text { [...] }\end{array}$ & Discussion of training needs. & Training \\
\hline $\begin{array}{l}\text { Staff nurse: I was just wondering... if the chief duty nurses are to } \\
\text { receive [the nursing staff's] sick leave notices of up to three days... } \\
\text { the situation will be difficult if I [as a chief duty nurse] receive } \\
\text { them but can't do the care group placements for the next days - } \\
\text { then I'd have to interrupt the manager who will take care of the } \\
\text { sick leave. I think that just cuts the ground from under the chief } \\
\text { duty nurses' feet... } \\
\text { [...] } \\
\text { Charge nurse: These care group placements take a lot of the } \\
\text { manager's time. Because I'm the one doing them. }\end{array}$ & $\begin{array}{l}\text { Planning and preliminary } \\
\text { decisions on the new division } \\
\text { of labour between the } \\
\text { charge nurse and the chief } \\
\text { duty nurse. }\end{array}$ & Identity work \\
\hline
\end{tabular}


Appendix 2. The coding of the brief summaries concerning participation practices

\begin{tabular}{|c|c|c|c|}
\hline Phase & Brief summary of the main content & $\begin{array}{l}\text { Practices facilitating } \\
\text { employee } \\
\text { participation }\end{array}$ & $\begin{array}{l}\text { Nature of employee } \\
\text { participation }\end{array}$ \\
\hline \multirow[t]{2}{*}{$\begin{array}{l}\text { Preparation } \\
\text { phase }\end{array}$} & $\begin{array}{l}\text { Discussion of problems in the clinic } \\
\text { (inadequate cleanliness in the treatment } \\
\text { rooms, problems with the patient data } \\
\text { system, training needs, shift rosters, } \\
\text { shortage of nurses in the trauma room, } \\
\text { backlogs) (Extract 7). }\end{array}$ & General discussion & $\begin{array}{l}\text { Weak: expressing } \\
\text { problems, question- } \\
\text { answer manner of } \\
\text { interacting }\end{array}$ \\
\hline & $\begin{array}{l}\text { The senior ward physician informed the } \\
\text { staff about the actions needed because of } \\
\text { the increased patient volume. General } \\
\text { discussion on proposed spatial changes in } \\
\text { the clinic (treatment rooms, etc.). Small- } \\
\text { group discussions on training needs, } \\
\text { shift rosters and, and secretary-triage } \\
\text { work pairs (Extract 8). }\end{array}$ & $\begin{array}{l}\text { General discussion } \\
\text { Small-group } \\
\text { discussion }\end{array}$ & $\begin{array}{l}\text { Weak: informing } \\
\text { Strong: suggestions for } \\
\text { new practices } \\
\text { Strong: suggestions for } \\
\text { new practices }\end{array}$ \\
\hline \multirow[t]{2}{*}{$\begin{array}{l}\text { Planning } \\
\text { phase }\end{array}$} & $\begin{array}{l}\text { The head nurse expresses her } \\
\text { disappointment in the staff (Extract 1), } \\
\text { which leads to the decision that the } \\
\text { planning of the change is the managers' } \\
\text { duty. } \\
\text { Discussion of and aim to solve the } \\
\text { problems which the staff had mentioned } \\
\text { in the first and second development } \\
\text { meetings, e.g. nursing resources in the } \\
\text { trauma room. Discussion of the new care } \\
\text { group model, and a decision to implement } \\
\text { it later than the other changes. Discussion } \\
\text { of the competencies required by the work } \\
\text { of the chief duty nurse, plus training } \\
\text { needs (Extract } 2 \text { ). Planning and } \\
\text { preliminary decisions on the duties of the } \\
\text { chief duty nurse and on the nurses who } \\
\text { would have the competence to work as } \\
\text { chief duty nurse. Planning and } \\
\text { preliminary decisions on the new } \\
\text { division of labour between the charge } \\
\text { nurse and the chief duty nurse (Extract } \\
\text { 3). Discussion of the principles } \\
\text { underlying the planning of shift rosters, } \\
\text { with preliminary decisions on new shift } \\
\text { rosters. Planning of the statutory co- } \\
\text { determination meeting, the new } \\
\text { practice of morning meetings in the } \\
\text { clinic and allocating ample nursing } \\
\text { resources for the beginning of the } \\
\text { implementation. }\end{array}$ & $\begin{array}{l}\text { Only the managers } \\
\text { participated }\end{array}$ & $\begin{array}{l}\text { Strong: Decisions on new } \\
\text { practices } \\
\text { Strong: Identity work } \\
\begin{array}{l}\text { Strong: Decisions on new } \\
\text { practices }\end{array}\end{array}$ \\
\hline & $\begin{array}{l}\text { The head nurse and chief physician } \\
\text { informed the staff about the changes. } \\
\text { Participants asked about the tight } \\
\text { schedule for carrying out the changes in } \\
\text { the treatment rooms and for recruiting } \\
\text { new nurses. There was information and } \\
\text { agreement concerning the principles of } \\
\text { shift rosters. }\end{array}$ & *) & $\begin{array}{l}\text { Weak: informing } \\
\text { Weak: question-answer } \\
\text { manner of interacting } \\
\text { Weak: expressing } \\
\text { problems } \\
\text { Weak: informing }\end{array}$ \\
\hline
\end{tabular}




\begin{tabular}{|c|c|c|c|}
\hline & $\begin{array}{l}\text { The charge nurse presented the } \\
\text { forthcoming changes in patient flows, } \\
\text { explained the ramifications for shift } \\
\text { rosters, informed about the recruitment } \\
\text { of new nurses, briefly explained the new } \\
\text { duties of the chief duty nurses, and } \\
\text { indicated how the new arrangements } \\
\text { would improve nurse resources in the } \\
\text { trauma room (Extract 4). Discussion of } \\
\text { the difficulty of the new duties, and } \\
\text { discussion of forthcoming training and } \\
\text { guidance. Discussion of group work in } \\
\text { the primary care group and in the care } \\
\text { group for conservative medicine. } \\
\text { Discussion and problem solving on shift } \\
\text { rosters. Discussion of the fast-track action } \\
\text { model, problems of triage, and the } \\
\text { importance of informing patients and the } \\
\text { general public. }\end{array}$ & $*)$ & Strong: problem-solving \\
\hline \multirow[t]{3}{*}{$\begin{array}{l}\text { Discussion } \\
\text { phase }\end{array}$} & $\begin{array}{l}\text { The head nurse and the charge nurse } \\
\text { presented the preliminary decisions on } \\
\text { the duties of chief duty nurses, the fast- } \\
\text { track action model, care groups, and shift } \\
\text { rosters. The participants presented } \\
\text { problems connected with e.g. the mandate } \\
\text { of chief duty nurses (Extract 9), triage, } \\
\text { and the shortage of nurses in the trauma } \\
\text { room. The staff made suggestions and } \\
\text { asked questions about training needs. } \\
\text { Discussion also on how patients and the } \\
\text { general public would be informed. }\end{array}$ & General discussion & $\begin{array}{l}\text { Weak: informing } \\
\text { Weak: expressing } \\
\text { problems } \\
\text { Strong: suggestions for } \\
\text { new practices }\end{array}$ \\
\hline & $\begin{array}{l}\text { The work of chief duty nurses was found } \\
\text { to comprise coordination of care groups } \\
\text { (e.g. handling backlogs), clinical work, } \\
\text { advising, problem-solving, and } \\
\text { motivating colleagues. Problems arose } \\
\text { from individual differences in } \\
\text { approaching the duties of chief duty } \\
\text { nurse (e.g. different interpretations of the } \\
\text { duties; diligence); mandate to do the job } \\
\text { (both formal, such as giving days off and } \\
\text { arranging substitutes, and informal, such } \\
\text { as respect from colleagues); and 'idle' } \\
\text { moments on the job (workload during } \\
\text { peaceful moments in the clinic, the } \\
\text { 'extent' of participation in routine clinical } \\
\text { work). Training arranged for triage } \\
\text { nurses but not for chief duty nurses. }\end{array}$ & & \\
\hline & $\begin{array}{l}\text { The researchers of this study arranged a } \\
\text { development meeting together with the } \\
\text { management of the clinic. Themes that } \\
\text { had emerged during the research project } \\
\text { were brought up for general discussion by } \\
\text { the researchers: coordination of the } \\
\text { clinic's collaboration, the new chief duty } \\
\text { nurse model, the fast track practice. As } \\
\text { for the chief duty nurse model, it was }\end{array}$ & & \\
\hline
\end{tabular}




\begin{tabular}{|l|l|l|l|}
\hline $\begin{array}{l}\text { generally viewed as good that there is one } \\
\text { person with an overview of the clinic's } \\
\text { situation and who can be consulted when } \\
\text { necessary. However, one surmised that } \\
\text { the duties of the chief duty nurse are not } \\
\text { necessarily clear to all care group nurses. } \\
\text { Discussion on the chief duty nurse's } \\
\text { participation in routine clinical work. } \\
\text { Chief duty nurses experienced major } \\
\text { simultaneous backlogs in all sections of } \\
\text { the clinic. Insufficiency experienced } \\
\text { concerning the major responsibility of } \\
\text { chief duty nurse. Training wanted e.g. on } \\
\text { actions in early stages of calamities, and } \\
\text { collaboration with the emergency ward. }\end{array}$ &
\end{tabular}

*) To find out the potential role of the statutory co-determination meeting in the planning of the change, we scrutinized the last planning meeting that occurred after the statutory co-determination meeting. However, we did not find any evidence of the meeting having an effect on the decisions of the planning group. The meeting of the work group for division of labour occurred after the last planning meeting; this chronology led to the inference (concerning the influence of the group in the change) presented in Table 3. 